\title{
O IDEB E A ATUAÇÃO DOCENTE NA PERSPECTIVA DA AUTORREGULAÇÃO
}

\author{
GISELE PESSIN ${ }^{1}$ \\ ORCID: https://orcid.org/0000-0003-0564-4537 \\ VERA LUCIA DEPS ${ }^{2}$ \\ ORCID: https://orcid.org/0000-0003-3994-2452
}

\begin{abstract}
RESUMO: A pesquisa objetivou analisar os impactos do Índice de Desenvolvimento da Educação Básica (IDEB) no Ensino Fundamental em decorrência da autorregulação do comportamento de professores. Realizou-se um estudo de caso comparativo entre duas escolas de uma Rede Municipal de Educação no Norte do Estado do Rio de Janeiro que estão, respectivamente, entre os maiores e menores resultados no IDEB em 2015. Trata-se de um estudo qualitativo realizado com docentes, orientadores pedagógicos e diretores. Os resultados das entrevistas e observações foram analisados por meio da Análise de Conteúdo e adotou-se a perspectiva teórica da Autorregulação. Constatou-se que a falta de clareza sobre os objetivos da avaliação do MEC comprometeu o planejamento de ações e a reflexão sobre os resultados. O êxito no IDEB aumentou a motivação para a manutenção de bons resultados, o que não ocorreu na escola que não alcançou a meta projetada pelo MEC. Além disso, ficou evidenciado que, frente à iminência da Prova Brasil, as regulações externas influenciam os professores para a preparação dos alunos.
\end{abstract}

Palavras-chave: IDEB, Autorregulação, Atuação docente.

\section{IDEB AND TEACHING PERFORMANCE FROM THE PERSPECTIVE OF SELF-REGULATION}

\begin{abstract}
This research aimed to analyze the Basic Education Development Index (IDEB) impact on Elementary School as a result of self-regulation of teachers' behavior. A comparative case study was carried out between two schools from a Municipal Education Network in Northern Rio de Janeiro State, which were, respectively, among the highest and the lowest IDEB results in 2015. It was a qualitative study carried out with teachers, pedagogical advisors and school principals. Interviews and observations results were analyzed based on Content Analysis from the theoretical perspective of self-regulation. It was found that the lack of clarity about the MEC (Ministry of Education) assessment objectives compromised the planning of actions and the reflection about the results. The success achieved in the IDEB increased motivation to maintain good results, which did not happen in the school that did not reach the goal projected by the MEC. In addition, it became evident that, faced with the imminence of Prova Brasil, the external regulations influence teachers to prepare students.
\end{abstract}

\footnotetext{
1 Universidade Estadual do Norte Fluminense Darcy Ribeiro (UENF). Campos dos Goytacazes, RJ, Brasil. $<$ pessingisa@gmail.com>

2 Universidade Estadual do Norte Fluminense Darcy Ribeiro (UENF). Campos dos Goytacazes, RJ, Brasil. <mielveh@uenf.br> 
Keywords: IDEB, Self-regulation, Teaching performance.

\section{EL IDEB Y LA ACTUACIÓN DOCENTE DESDE LA PERSPECTIVA DE LA AUTORREGULACIÓN}

RESUMEN: La investigación tuvo como objetivo analizar los impactos del Índice de Desarrollo de la Educación Básica (IDEB) en la Educación Primaria como resultado de la autorregulación del comportamiento de los profesores. Se realizó un estudio de caso comparativo entre dos escuelas de una Red Municipal de Educación en el Norte del Estado de Rio de Janeiro que estuvieron, respectivamente, entre los mayores y menores resultados del IDEB en el año 2015. Se trata de un estudio cualitativo realizado con docentes, orientadores pedagógicos y directores. Los resultados de las entrevistas y de las observaciones fueron analizados por medio de Análisis de Contenido e se adoptó la perspectiva teórica de la Autorregulación. Se constató que la falta de claridad respecto a los objetivos de la evaluación del MEC (Ministerio de Educación) comprometió la planificación de acciones y la reflexión sobre los resultados. El éxito en el IDEB aumentó la motivación para mantener buenos resultados, lo que no ocurrió en la escuela que no alcanzó la meta proyectada por el MEC. Además, se evidenció que, ante la inminencia de la Prova Brasil, las regulaciones externas influyen en los profesores para la preparación de los estudiantes.

Palabras clave: IDEB, Autorregulación, Actuación docente. 


\section{INTRODUÇÃO}

Frente aos Índices de Desenvolvimento da Educação Básica (IDEB) divulgados pelo Ministério da Educação (MEC) e à constatação de altas taxas de repetência e evasão, o Plano Nacional de Educação (PNE), sancionado em 2014 e com vigência de dez anos, apresenta objetivos importantes para a superação das dificuldades presentes. Dentre as estratégias elencadas, o PNE afirma a necessidade de promover o desenvolvimento de tecnologias educacionais e práticas pedagógicas inovadoras, bem como de utilizar instrumentos que favoreçam a autoavaliação das escolas, incentivando o monitoramento contínuo, tendo em vista a melhoria da qualidade educacional. Além disso, vale mencionar que, entre as estratégias destacadas, também está a preocupação com a formação dos profissionais da educação, dada a sua importância para os processos educacionais.

A partir de uma perspectiva formativa e considerando as proposições do PNE, reconhecese a importância dos processos de avaliação no cotidiano da escola, uma vez que eles podem oferecer subsídios importantes para mudanças necessárias nas instituições educacionais. Avaliações que incentivam a reflexão contribuem para a identificação de dificuldades, assim como podem estimular indivíduos e instituições a desenvolverem estratégias mais efetivas para o alcance dos objetivos educacionais. Podem, ainda, fundamentar a construção de políticas públicas para a melhoria da qualidade da educação no país.

Nesse sentido, além das avaliações que acontecem no dia a dia da escola, é importante conhecer a influência das avaliações externas no contexto escolar, mais especificamente na atuação dos professores. Tais considerações motivaram a realização de uma pesquisa com o objetivo de analisar o impacto do IDEB na atuação docente em escolas de Ensino Fundamental ( $1^{\circ}$ ao $5^{\circ}$ ano), utilizando como referencial a Teoria da Autorregulação (BANDURA, 1986; 2001; PINTRICH, 2000; 2004; ZIMMERMAN, 2000).

Especificamente, trata-se de um estudo de caso comparativo, de natureza qualitativa (BOGDAN; BIKLEN, 1994), realizado em duas escolas de uma Rede Municipal localizada no Norte Fluminense que se situam, respectivamente, entre aquelas que demonstraram os maiores e menores resultados no IDEB em 2015 e foram nomeadas aqui como "escola A" e "escola B". Ambas as escolas se situam na região central da cidade. No total, participaram da pesquisa 15 mulheres, sendo 11 professoras (escola A: 07; escola B: 04), além de duas orientadoras pedagógicas ou pedagogas (escola A: 01; escola B: 01) e duas diretoras (escola A: 01; escola B: 01). A disparidade entre o número de professoras das escolas deve-se à rotatividade de profissionais da escola B. Suas idades variavam entre 29 e 63 anos, possuíam experiência maior ou igual a cinco anos e atuavam em suas respectivas escolas há mais de dois anos.

O projeto de pesquisa que orientou este estudo foi submetido, avaliado e aprovado pelo Comitê de Ética em Pesquisa com seres humanos (CAAE n ${ }^{\circ}$ 79061517.3.0000.5244) e atendeu às determinações éticas da Resolução n 466/2012 do Conselho Nacional de Saúde. Após a autorização da Secretaria Municipal de Educação, efetivou-se o contato com as diretoras de ambas as escolas e, posteriormente, com as orientadoras pedagógicas e professores do $1^{\circ}$ ciclo do Ensino Fundamental. Todos foram informados sobre os objetivos do estudo e assinaram um Termo de Consentimento Livre e Esclarecido. Individualmente, os sujeitos preencheram o questionário de caracterização e posteriormente foram convidados a participar das entrevistas, que foram gravadas em áudio para posterior transcrição. Os dados foram organizados em categorias temáticas por meio da Análise de Conteúdo (BARDIN, 1979) e refletidos sob a luz da teoria adotada.

Parte-se do pressuposto de que a Teoria da Autorregulação aplicada à Educação oferece um importante arcabouço teórico para o estudo do impacto do IDEB no cotidiano escolar, possibilitando a compreensão das diferentes dimensões envolvidas na atuação docente quanto aos aspectos cognitivos, motivacionais, contextuais e comportamentais. De modo dinâmico, a referida teoria compreende que a autorregulação do comportamento envolve diferentes fases, desde o planejamento de ações até a execução e avaliação, visando ao alcance de objetivos previamente definidos.

Os resultados apresentados neste artigo representam um recorte de um estudo mais amplo, que investigou a autorregulação do comportamento dos professores relacionada à avaliação do MEC na Educação Básica em diferentes momentos (antes, durante e após a avaliação). 
$\mathrm{Na}$ análise dos resultados, percebeu-se a importância do momento anterior à avaliação, ou seja, da fase de planejamento para a atuação docente e, sobretudo, do conhecimento dos docentes sobre os objetivos da avaliação do MEC, o que motivou a delimitação dessa fase para a construção deste artigo. Por conseguinte, serão apresentados os resultados que correspondem ao comportamento dos professores e que antecedeu a realização da Prova Brasil em 2015.

\section{A AUTORREGULAÇÃO NO CONTEXTO EDUCACIONAL}

Sob o conceito de agência humana, Albert Bandura (2001; 1986), precursor da Teoria Social Cognitiva, considera que os seres humanos podem influenciar os eventos e produzir mudanças significativas no contexto e até mesmo no seu próprio curso de vida, de modo intencional. Nessa perspectiva, a compreensão do comportamento humano se dá a partir das interações recíprocas entre fatores cognitivos (e outros fatores pessoais), o comportamento e o ambiente, que formam uma tríade de influências dinâmicas (BANDURA, 1986).

A agência humana pressupõe intencionalidade, antecipação e autorregulação (BANDURA, 2001). Nesse sentido, as pessoas são capazes de criar objetivos, estabelecer planos de ação e canalizar seus esforços para o alcance das metas desejadas. Especificamente, a autorregulação envolve a regulação do comportamento por meio de auto-observações, julgamentos e autorreações avaliativas que influenciam as ações subsequentes de uma pessoa (BANDURA, 1986).

Considera-se que Pintrich $(2000 ; 2004)$ tenha apresentado um modelo apropriado para a compreensão de inúmeros fatores que se fazem presentes no processo educacional, compreendendo a autorregulação como um processo dinâmico que envolve diferentes fases (planejamento, execução e avaliação) e dimensões (metacognitiva, motivacional, comportamental e contextual). Em resumo, no contexto educacional, a autorregulação consiste em um processo ativo e construtivo no qual os sujeitos monitoram, regulam e controlam sua cognição, motivação, comportamento e contexto, tendo em vista os objetivos que se pretende alcançar (PINTRICH, 2000; 2004).

Entre as dimensões da autorregulação, a de natureza metacognitiva engloba os conhecimentos do indivíduo sobre si mesmo e sobre os outros, os conhecimentos relativos à tarefa e às estratégias. Também compreende o planejamento, monitorização e controle da própria atividade cognitiva (PINTRICH, 2000; 2004).

A motivação igualmente representa uma importante dimensão da autorregulação. Lopes da Silva (2004, p. 25) considera que a ação autorregulada pressupõe a existência de "um motivo que a incite e sustenha e que prolongue o esforço" até a meta desejada. Estudos têm enfatizado a importância das crenças para o comportamento motivado, tais como as crenças de autoeficácia (BANDURA, 1999; 2012), as atribuições de valor e expectativas (WIGFIELD; ECCLES, 2000), o lócus de controle (LEFCOURT, 2014), bem como as metas ou objetivos de realização (PINTRICH, 2000).

A dimensão comportamental também é fundamental para a execução das ações planejadas e inclui a seleção e implementação de estratégias, tais como aquelas relacionadas à correção dos procedimentos e a solicitação de ajuda quando necessário, visando ao alcance dos objetivos definidos (LOPES DA SILVA, 2004).

Por sua vez, a dimensão contextual diz respeito aos vários aspectos do ambiente circundante ao indivíduo, incluindo o contexto social e cultural, que podem favorecer ou constituir desafios ao comportamento autorregulado (PINTRICH, 2000; 2004).

Pintrich $(2000 ; 2004)$ ressalta que as fases da autorregulação não representam um processo linear e estático, podendo se sobrepor ou ocorrer simultaneamente, com interações múltiplas entre os diferentes componentes do processo.

Em todas as fases são considerados aspectos relacionados às dimensões que englobam o comportamento autorregulado. Para exemplificar essa dinâmica de acordo com o modelo de Pintrich (2000; 2004), pode-se observar a fase prévia, que inclui o planejamento: nessa fase são analisados aspectos de natureza metacognitiva, tais como a definição de objetivos, a reflexão sobre os metaconhecimentos, que abrange a avaliação do nível de dificuldade da tarefa, dos recursos pessoais e das estratégias adequadas para o alcance dos objetivos estabelecidos, dentre outros. Também na fase prévia estão presentes os aspectos motivacionais envolvidos, relacionados às crenças do indivíduo vinculadas ao 
objetivo pretendido e às estratégias de controle da motivação. Inclui ainda, aspectos de natureza comportamental, que dizem respeito à avaliação do esforço necessário para a realização da tarefa, bem como da disponibilidade de tempo para a realização. Por fim, a fase de planejamento envolve também a dimensão contextual, que implica a análise das condições do ambiente para o planejamento de estratégias visando à superação das condições adversas encontradas, por exemplo.

Considerando a dinâmica desse processo, é importante destacar a sua circularidade. Os feedbacks ou a avaliação sobre o desempenho possibilitam ajustes pessoais, comportamentais e ambientais necessários ao alcance dos objetivos, mediante a reflexão dos indivíduos (ZIMMERMAN, 2000).

No processo de ensino e aprendizagem, a autorregulação não é resultado exclusivo de esforços individuais, envolvendo inúmeros fatores, como as oportunidades e as interações favorecidas pelo professor no contexto escolar (MCCASLIN, 2009). Com o seu comportamento, em sua atuação, o docente representa um facilitador para aprendizagem da autorregulação do comportamento dos alunos (HADJI, 2011).

Mediante a transposição do conceito da autorregulação (BANDURA, 1986; PINTRICH, 2000; 2004; ZIMMERMAN, 2000) para o comportamento do professor, é importante considerar que a sua atuação pressupõe:

a) Clareza sobre os objetivos pessoais e institucionais, relacionados à atuação;

b) Comportamento antecipatório, através do planejamento das ações;

c) Motivação para impulsionar e sustentar o comportamento em direção aos objetivos definidos;

d) Monitorização dos próprios processos cognitivos, que envolve a reflexão sobre os seus conhecimentos e competências, sobre os objetivos e exigências da tarefa;

e) Atuação autônoma e ativa na construção de estratégias para produzir mudanças no contexto de atuação, envolvendo esforços para o alcance da meta desejada;

f) Autoavaliação contínua, que impulsione a reflexão sobre a própria ação e sobre as diversas variáveis que influenciam os processos de ensino e aprendizagem.

Desse modo, considera-se que a atuação do professor é influenciada pelo grau de autorregulação do seu próprio comportamento, considerando que este está inserido em um contexto onde experimenta simultaneamente os papéis de mestre e de aprendiz, como sinaliza McCaslin (2009).

Ainda no esforço de definir a autorregulação, cabe destacar que ela não se desenvolve somente com a maturação, nem é adquirida passivamente no ambiente. Conforme autores que estudam a autorregulação acadêmica, esta se refere a um processo contínuo de aprendizagem e desenvolvimento de habilidades (SCHUNK; ZIMMERMAN, 1997) que possibilita uma atuação autônoma e ativa no alcance dos próprios objetivos (PINTRICH, 2000; 2004). Nesse processo, a avaliação tem um papel fundamental, na medida em que possibilita a reflexão sobre a própria atuação e, sobretudo, quando favorece feedbacks que conduzem à autorregulação (HATTIE; TIMPERLEY, 2007).

Em escolas públicas, professores também recebem feedback do trabalho realizado no contexto escolar através das avaliações realizadas pelo MEC, que resultam na divulgação do IDEB, conforme apresentado a seguir.

\section{O IDEB: FEEDBACK PARA AS ESCOLAS E REDES DE ENSINO}

Além das avaliações que ocorrem no dia a dia da sala de aula das escolas públicas, estas instituições são submetidas a avaliações externas que objetivam aferir a qualidade da educação oferecida à população. A partir do Sistema de Avaliação da Educação Básica (SAEB), calcula-se o IDEB, que consiste em um indicador de desempenho do sistema educacional brasileiro, aferido a partir das notas obtidas pelos estudantes em provas de proficiência em língua portuguesa e matemática (Avaliação Nacional do Rendimento Escolar-Anresc/Prova Brasil), somadas aos dados do fluxo escolar. Esses dados são obtidos pela média de aprovação dos estudantes ou pelo tempo médio de conclusão de uma série. Esses dados são verificados a partir do Censo Escolar, realizado anualmente nas escolas, sob a coordenação do INEP (Instituto Nacional de Estudos e Pesquisas Anísio Teixeira). 
Em resumo técnico sobre o IDEB de 2015, o INEP intencionou que os resultados fossem apropriados pelos gestores das escolas e pela sociedade em geral, de modo que suscitassem reflexões para a melhoria da educação:

Os resultados das escolas e dos municípios brasileiros [...] e a análise desses dados [...] serão fundamentais para que um diagnóstico mais robusto seja oferecido aos gestores das diferentes instâncias administrativas, contribuindo para auxiliar na orientação de ações e políticas, visando à melhoria do desempenho da educação brasileira. Acrescenta-se a isso as iniciativas de sucesso que os dados podem revelar. É importante que tais iniciativas sejam identificadas e estudadas e que, eventualmente, possam inspirar atitudes em prol da consolidação de uma cultura que valorize o aprendizado, sem, entretanto, desconsiderar outras dimensões para que efetivamente o País alcance um patamar mais avançado de qualidade da educação que oferece às suas crianças (INEP, 2016, p. 56).

Supostamente, numa escala de 0 a 10, quanto maior for o índice obtido pela escola ou rede de ensino, maior será a efetividade da educação naquele contexto. Nesse sentido, tais índices mostram a necessidade de melhorias ou sugerem que a instituição escolar ou o sistema de ensino oferecem um ensino de qualidade.

Embora os resultados do IDEB sejam tratados pelo INEP como um fiel diagnóstico da realidade da educação brasileira, com diversas possiblidades de desdobramentos para a melhoria das condições de aprendizagem dos alunos, não existe um consenso entre os pesquisadores dessa temática. Alguns autores questionam o modo pelo qual essa avaliação é realizada, bem como os seus limites (ALMEIDA; DALBEN; FREITAS, 2013; OLIVEIRA, 2013; SOARES; XAVIER, 2013; SCHNEIDER; NARDI, 2014).

É importante considerar que o IDEB representa uma avaliação efetivada a partir de um recorte, tanto das disciplinas, quanto dos estudantes que correspondem aos anos de escolaridade contemplados. Apesar dos inúmeros questionamentos existentes em relação ao IDEB, Soares e Xavier (2013) compreendem que a avaliação deve ser tomada como um primeiro passo para a busca de efetivas práticas pedagógicas e melhores condições para a aprendizagem dos alunos. Fernandes (2016) acredita na ocorrência de melhorias nas condições de ensino-aprendizagem, influenciadas pelo conjunto de ações contemplado pelo IDEB. Sabe-se que as escolas não estão alheias à implementação de políticas públicas, e a divulgação dos resultados do IDEB causa impacto no seu cotidiano (MESQUITA, 2012).

A medida é apenas uma das dimensões dos processos de avaliação, e deve envolver análises e proposições a partir dela (OLIVEIRA, 2013). Estudos têm sinalizado para a importância da avaliação, sobretudo quando realizada sob uma perspectiva formativa (HADJI, 2011), conduzindo à autorregulação dos sujeitos (HATTIE; TIMPERLEY, 2007). As avaliações podem fornecer informações essenciais para o alcance de objetivos e metas educacionais, fornecendo pistas para a superação de dificuldades, em um percurso de aprimoramento contínuo. Por esse motivo, são imprescindíveis para a reflexão e para o monitoramento das ações realizadas no cotidiano escolar e devem ocorrer de modo mais abrangente, observando a complexidade do processo educacional, como sugerem Almeida, Dalben e Freitas (2013). Amaro (2017) propõe que as pesquisas sobre a temática também incluam os processos que antecedem e sucedem a realização da Prova Brasil, sob uma perspectiva contrarregulatória.

Ainda que exista uma variedade significativa de investigações sobre o IDEB e suas repercussões no ambiente escolar, até o presente momento essa temática não foi estudada a partir da perspectiva da autorregulação, objeto deste estudo. Embora represente uma abordagem recente no Brasil, essa perspectiva tem sido desenvolvida por pesquisadores de diferentes enfoques no contexto internacional, revelando sua grande aplicabilidade e relevância para a Educação. Ao mesmo tempo, por valorizar a importância dos processos de avaliação para o alcance de objetivos educacionais, tal perspectiva apresenta-se como um importante arcabouço teórico para a análise da efetividade do IDEB e do seu impacto no cotidiano das escolas, em decorrência da atuação autorregulada dos professores. 


\section{O COMPORTAMENTO DOS PROFESSORES DIANTE DA EMINÊNCIA DA PROVA BRASIL: AUTORREGULAÇÃO OU REGULAÇÃO EXTERNA?}

Como mencionado, os resultados apresentados focalizaram a fase prévia de planejamento e as respectivas dimensões da autorregulação, que representam as categorias temáticas organizadas a partir da Análise de Conteúdo (BARDIN, 1979). Neste estudo, a fase prévia de planejamento corresponde ao período que antecedeu a realização da avaliação do MEC no $1^{\circ}$ ciclo do Ensino Fundamental nas escolas observadas. Especificamente, trata-se da autorregulação da atuação dos professores em momento anterior à avaliação do MEC em 2015, conforme apresentado no Quadro 1:

QUADRO 1. A fase prévia ou de planejamento e as suas diferentes dimensões, integrando as variáveis observadas neste estudo

\begin{tabular}{|c|c|c|c|c|c|}
\hline \multirow[b]{2}{*}{ FASE } & \multicolumn{5}{|c|}{ DIMENSÕES } \\
\hline & Metacognitiva & Motivaciona & & Comportamental & Contextual \\
\hline Planejamento & $\begin{array}{l}\text { Conhecimentos } \\
\text { prévios } \\
\text { relacionados à } \\
\text { avaliação do } \\
\text { MEC; análise dos } \\
\text { resultados } \\
\text { obtidos } \\
\text { anteriormente; } \\
\text { estabelecimento } \\
\text { de objetivos; }\end{array}$ & $\begin{array}{l}\text { Crenças } \\
\text { relacionadas } \\
\text { avaliação e } \\
\text { desempenho } \\
\text { (atribuição } \\
\text { valor } \\
\text { expectativa } \\
\text { resultado; } \\
\text { crenças } \\
\text { autoeficácia; } \\
\text { orientação } \\
\text { meta; lócus } \\
\text { controle); }\end{array}$ & $\begin{array}{l}\text { à } \\
\text { ao } \\
\text { de } \\
\text { e } \\
\text { de } \\
\text { de }\end{array}$ & $\begin{array}{l}\text { Delineamento das } \\
\text { estratégias; } \\
\text { Planejamento; } \\
\text { Identificação da } \\
\text { necessidade de } \\
\text { apoio ou ajuda; }\end{array}$ & $\begin{array}{l}\text { Percepções sobre } \\
\text { a adequação do } \\
\text { contexto para a } \\
\text { realização das } \\
\text { tarefas; }\end{array}$ \\
\hline
\end{tabular}

Fonte: Adaptação do modelo de Pintrich (2000; 2004) pelas autoras.

É importante esclarecer que, para preservar o sigilo sobre as identidades dos sujeitos, seus nomes foram omitidos. Em suas falas, os sujeitos foram identificados pelas iniciais da função que ocupavam e a escola onde atuavam. Nos relatos das professoras, acrescentou-se um número aleatório, de acordo com a quantidade de entrevistadas. Exemplificando, na escola A as professoras foram identificadas entre P.A.1 e P.A.7.

A seguir, apresentam-se as categorias que constituem as diferentes dimensões do comportamento autorregulado dos professores.

\section{Dimensão metacognitiva}

Faz parte dessa dimensão a ativação dos conhecimentos prévios relacionados à avaliação do MEC, a análise dos resultados obtidos na avaliação anterior, o estabelecimento de objetivos em decorrência dessa avaliação. Como uma dimensão imprescindível para a autorregulação, a metacognição implica em reflexão sobre os objetivos educacionais e sobre a própria atuação no decorrer de todo o processo.

Para compreender o impacto da avaliação do MEC nas escolas a partir da autorregulação do comportamento dos professores, é importante compreender o funcionamento do processo desde o seu início. Nesse caso, considera-se que o acesso a informações sobre a avaliação do MEC nas escolas possibilita a ativação de conhecimentos prévios necessários ao planejamento.

Em período próximo à aplicação da Prova Brasil, as Diretoras das escolas pesquisadas foram informadas pela Secretaria de Educação sobre a ocorrência dessa avaliação, comunicando a data em que 
seria realizada. No entanto, a Diretora da escola A sinalizou que já existia uma expectativa anterior à avaliação em sua unidade:

A gente é informada perto da prova. Antes, a rede toda fica em aberto, porque o Governo escolhe as escolas. Todo mundo fica na expectativa e quando chega, geralmente, acho que em agosto ou setembro, eles entram em contato, dizendo o dia da prova, e que a minha escola foi selecionada. A gente não tem um conhecimento antes, não. Sabemos que a rede vai ser avaliada, então terminamos uma prova e começamos a fazer um trabalho para a outra (D.A.).

Percebeu-se que, nessa escola, os profissionais já esperavam pela avaliação do MEC e já se preparavam para a sua ocorrência, antes de qualquer comunicado oficial por parte da Secretaria de Educação. Essa expectativa presente na escola A não foi percebida na escola B, apesar da Pedagoga atuar no sentido de informar e mobilizar os docentes para a preparação dos estudantes em decorrência da avaliação do MEC, conforme relato de uma professora:

A OP [Orientadora Pedagógica] informou sobre a Prova Brasil. Não se reuniu com a escola toda. Ela vai nas salas de aula e conversa com a gente. Ela é quem passa tudo pra gente sobre a prova (P.B.4).

Na escola A, a Diretora e a Pedagoga também procuravam mobilizar os professores e informá-los a respeito da Prova Brasil, segundo os próprios docentes. Ao serem informados sobre a realização da avaliação, intensificavam o trabalho de preparação dos alunos, que vinha sendo realizado, conforme o depoimento seguinte:

A informação nos chega pela direção e nós já preparamos nossos alunos em função disso, porque sabemos que essa avaliação acontecerá. Nós sempre focamos no que será cobrado, como será cobrado e vamos praticando. Como se fosse um ENEM. Já vai trabalhando, pra quando chegar a prova não ser nenhuma novidade [ para os alunos], para não pegá-los de surpresa na maneira que seriam cobrados (P.A.1).

Em relação aos professores, em princípio, os docentes do $5^{\circ}$ ano, tanto os da escola $\mathrm{A}$ quanto os da escola B, por atuarem nas séries em que os alunos realizariam a Prova Brasil, foram informados antes dos demais sobre a avaliação do MEC e receberam orientações sobre a preparação dos estudantes para a Prova Brasil. $\mathrm{Na}$ escola A, uma professora relatou:

Em 2015, eu estava na turma do $5^{\circ}$ ano. Toda informação que chega da Secretaria de Educação, a direção da escola junto com a orientação pedagógica fazem questão de passar para gente com muita clareza, as informações. Durante a preparação, me falavam "olha, temos que trabalhar os descritores". Também tinham os cursos que sempre eram passados com as datas corretas e nós frequentávamos as capacitações. Quando elas tinham alguma dúvida, elas buscavam saber para nos passar (P.A.4).

$\mathrm{Na}$ escola B, esse processo de mobilização dos professores do $5^{\circ}$ ano foi difícil, segundo os relatos da Pedagoga. Ela mencionou dificuldades enfrentadas pela escola:

Em 2015, a nossa escola teve o pior índice, em relação às demais escolas do município. Nesse quinto ano avaliado, teve troca de professores. [...] Nós tivemos um caso seríssimo aqui, mas sério mesmo em 2015. Essa turma chegou a ficar em casa. Foi difícil (O.P.B.).

Tal relato evidencia as dificuldades vivenciadas na escola $\mathrm{B}$, no ano em que receberam um resultado insatisfatório. A rotatividade de professores pode ter influenciado o processo de planejamento de ações nesse contexto. É importante observar, ainda, que havia o predomínio de regulações externas nessa escola: após o contato da Secretaria de Educação, a pedagoga tentava mobilizar os professores, mas isso não era suficiente para mobilizar a construção de um planejamento para a ação. As comunicações costumavam ocorrer de modo individualizado na escola $\mathrm{B}$, de acordo com as necessidades que se apresentavam, o que aponta para uma realidade constatada através da observação: havia raros 
momentos coletivos de planejamento e reunião com os professores. $\mathrm{Na}$ escola $\mathrm{A}$, por sua vez, os professores eram influenciados pela Diretora e pela Pedagoga, mas cabe considerar a existência de uma mobilização que nascia no próprio ambiente escolar, mostrando sinais de autorregulação.

No processo de autorregulação, a definição de objetivos é condição sine qua non para a elaboração do planejamento e de todos os procedimentos a ele inerentes (PINTRICH, 2000; 2004). Neste estudo, foram observados os conhecimentos das participantes sobre os objetivos da avaliação do MEC em suas escolas e a sua apropriação. Para isso, a análise dos resultados anteriores deveria ser considerada.

Durante a pesquisa, constatou-se uma diferença entre os profissionais da escola que apresentou resultado satisfatório em 2015, em comparação aos profissionais da escola que obteve baixo resultado. Na primeira, todos conheciam o resultado obtido anteriormente; o mesmo não ocorreu na segunda. Ao serem perguntados se consideraram o resultado da avaliação de 2013 no planejamento de 2015, uma professora da escola B comentou que não se lembrava do resultado anterior:

A Pedagoga sempre passa para a gente, mas eu não me lembro direito o resultado de 2013, não estou lembrando... (P.B.4)

Em contrapartida, na escola $\mathrm{A}$, as professoras apresentaram resposta afirmativa e, ao mesmo tempo, demonstraram orgulho do resultado:

A escola conseguiu elevar a nota. A gente conseguiu ficar com a nota maior que o esperado. Tivemos como comparar e foi ótimo ver o resultado de tudo que a gente preparou (P.A.7).

Todavia, assim como na escola $\mathrm{B}$, não ocorreu uma análise dos resultados anteriores na escola A:

A gente não buscou a fundo sobre os resultados. Não sei te dizer qual é a porcentagem que formou o resultado final. Como os alunos foram na prova? Tiraram nota melhor em matemática ou português? Gostaria até de saber... (P.A.6).

A análise dos resultados obtidos anteriormente é imprescindível para a construção do planejamento, pois se pressupõe que os profissionais devem partir dos pontos de fragilidade e das competências observadas para construírem seus objetivos e alcançá-los, como preconiza a literatura especializada (ZIMMERMAN, 2000).

Quanto ao conhecimento sobre o objetivo da avaliação do MEC, constatou-se que, dentre os professores, quando indagados sobre esse assunto, nem todos demonstraram conhecimento aprofundado. Vê-se o relato de uma professora da escola B:

Antes de eu vir pra cá, eu trabalhava em outro lugar. Lá, ainda não tinha chegado a prova Prova Brasil]. Não sei se depois que eu vim pra cá passou a ter. Não sei te informar. Mas fui saber sobre a prova aqui mesmo. Aqui, foi a primeira vez. Já fui do $2^{\circ}$ ano e já participei do $2^{\circ}$ ano aqui com a Prova Brasil (P.B.4).

O relato da docente demonstra um conhecimento equivocado sobre a avaliação. A mesma relata a experiência com a Prova Brasil no $2^{\circ}$ ano de escolaridade; entretanto, essa prova só é aplicada no $5^{\circ}$ ano, isto é, ao final do primeiro ciclo do Ensino Fundamental. O relato de uma professora da escola A também revela que a mesma não conhecia os objetivos dessa avaliação com profundidade:

A Prova [Prova Brasil] eu já conhecia. Mas assim, os objetivos, especificamente, eu não saberia detalhar (P.A.3).

Outras professoras da escola A também não apresentaram conhecimento aprofundado sobre os propósitos do MEC. Contudo, a resposta da professora da escola B à pergunta sobre os objetivos da avaliação do MEC revelou um nível ainda maior de desinformação. 
Por ser a Prova Brasil aplicada somente aos alunos do $5^{\circ}$ ano, há maior preocupação e cobrança no contexto escolar dos professores que atuam nessa série. Como mencionado anteriormente, assim que a Secretaria de Educação comunicou à Direção e à Pedagoga sobre a ocorrência da Prova Brasil, estas informaram aos professores, mas com maiores detalhes àqueles que atuavam no $5^{\circ}$ ano. Além disso, a estes professores foi oferecida, pela Secretaria Municipal de Educação, a oportunidade de participarem de encontros de capacitação em preparação para a realização da Prova Brasil.

O relato abaixo sinaliza a importância das capacitações frente às dificuldades enfrentadas pelos professores no processo de preparação dos alunos para a Prova Brasil. Ao mesmo tempo, aponta a discrepância existente entre o currículo trabalhado em sala de aula e os descritores da referida avaliação:

As capacitações eram feitas pela Secretaria de Educação. [...] Na medida em que os conteúdos do curso eram apresentados, os professores tinham muitas dúvidas e ali no curso mesmo eles tentavam ajudar, explicar de alguma forma. A primeira prova que eu participei como professora, eu estranhei muito aquele material todo. [...] Nos encontros que havia nessas capacitações, às vezes dava uma luz pra quem estava muito perdido. [...] Tem gente que tem muita dificuldade de fazer a avaliação integrada. Integrar uma avaliação facilita para você estar trabalhando com essa questão dos descritores. Facilita muito. Entendeu, é um exercício diário (P.A.4).

O depoimento anterior sinaliza que a capacitação deveria ser mais abrangente, no sentido de incluir os professores das séries anteriores para que estes também pudessem se apossar dos objetivos da avaliação realizada pelo MEC, refletir sobre sua adequação e viabilidade, planejar as ações a serem desenvolvidas e construir metas, tendo em vista o alcance de objetivos pessoais e educacionais, para além da avaliação pontual.

É importante sinalizar que os professores da escola A que participaram da capacitação mencionaram que essa oportunidade não somente os auxiliou a trabalhar com os descritores em sua atuação, mas também lhes possibilitou desenvolver estratégias de ensino e de avaliação com foco interdisciplinar. Talvez tenha se perdido aí uma oportunidade de um envolvimento coletivo no processo, buscando-se alternativas para uma escolarização mais bem sucedida, o que possivelmente se reverteria favoravelmente no bom desempenho dos alunos.

Constatou-se também a importância da atuação das lideranças escolares junto às práticas pedagógicas da escola, o que foi ressaltado pelos professores da escola A como fator importante para os seus bons resultados:

[...] Aqui, o apoio da Direção é o diferencial. Aqui, a gente tem o apoio de toda a equipe. A missão não é só minha. A missão não é só dela. Então, eu acho que isso facilita muito o trabalho, quando você sabe que não está sozinha. [...] A gente tem a coordenadora pedagógica e ainda tem a diretora que também nos dá suporte pedagógico. Talvez por ela ser pedagoga, ser supervisora, ela tem uma visão que nos ajuda bastante (P.A.6).

Percebe-se, no relato da professora, a influência das interações com os pares em sua própria atuação, sugerindo a existência de construções coletivas, que deflagram um objetivo compartilhado, conforme o relato:

O que eu acho importante é que desde o primeiro momento, tanto a diretora quanto a Pedagoga colocaram que a responsabilidade não é só do professor do quinto ano. Há todo um trabalho de equipe, porque a avaliação é feita no $5^{\circ}$ ano, mas tem outros fatores que vão influenciar também positivamente ou negativamente no resultado geral da escola. Então há uma conscientização para que todas as professoras se empenhem para que o resultado seja bom. Há um comprometimento de todos. [...] A gente começou desde o início do ano priorizando a Prova Brasil. Era uma das metas que a gente tinha (P.A.2).

Além disso, não obstante tivesse sido percebida na escola $\mathrm{A}$, em comparação à escola $\mathrm{B}$, a realização de procedimentos mais adequados visando ao alcance dos resultados desejados, se os professores tivessem, em suas atuações, maior autonomia e refletissem mais sobre o trabalho que realizavam e sobre si mesmos, poderiam alcançar resultados ainda melhores. 
O estabelecimento de metas envolve um processo de busca por algo que se almeja realizar ou atingir, como um alvo (ZIMMERMAN, 2000). Os objetivos representam, assim, um critério que norteia o monitoramento do progresso em direção à meta desejada (PINTRICH, 2000; 2004). Ainda que também estivessem influenciados por regulações externas, os profissionais da escola A tinham convicção sobre o objetivo que pretendiam: obter um bom resultado na avaliação do MEC. Na escola B, por outro lado, acredita-se que a falta de clareza sobre a avaliação do MEC, o baixo engajamento para a construção de objetivos, assim como a ausência de momentos coletivos de reflexão, dificultou todo o processo de planejamento para a atuação e deflagrou o baixo nível de autorregulação.

Vale considerar, ainda, que o meio social também influencia os processos de autorreflexão e autoavaliação, que podem ser favorecidos pela instrução, feedback e incentivos recebidos (ZIMMERMAN, 2000). Observou-se que em ambas as escolas esses processos devem receber maior investimento. Contudo, a maior presença de incentivos e instruções na escola A certamente contribuiu para uma maior adesão ao objetivo compartilhado.

Além da dimensão metacognitiva, também estão implicados no processo de autorregulação os aspectos motivacionais, explicitados a seguir.

\section{Dimensão motivacional}

De acordo com a perspectiva da autorregulação, as crenças relacionadas aos objetivos a serem alcançados, assim como a participação ativa em todo o processo de construção desse objetivo, constituem condição imprescindível para impulsionar a motivação das pessoas. No contexto da educação, embora os documentos oficiais mencionem a importância da participação ativa dos docentes no processo de elaboração de políticas públicas, muitos objetivos foram elaborados sem a participação dos profissionais que atuam nas Escolas, e isso ocorreu com a proposta de avaliação do MEC para a constituição do IDEB.

A partir da perspectiva da autorregulação, considera-se que a construção de objetivos significativos, associada ao engajamento pessoal e coletivo para o alcance deles, está diretamente relacionada às crenças dos profissionais da educação, como as crenças de autoeficácia, as atribuições de valor e as expectativas de resultado, o lócus de controle, bem como a orientação à meta.

Paralelamente à reflexão sobre os objetivos da avaliação do MEC, é igualmente importante questionar se de fato foi construída uma atribuição de valor favorável por parte desses profissionais a respeito do objetivo que lhes foi imposto. No que diz respeito a essa atribuição de valor, ao serem perguntados sobre a importância da avaliação do MEC, os profissionais da escola A e os da escola B afirmaram reconhecer a importância dessa avaliação. Na escola B, a Pedagoga valorizou as avaliações enquanto um "termômetro":

Eu acredito que seja importante, porque toda avaliação representa um termômetro, entre aspas, do conhecimento do alunado e nos dá uma resposta em relação a isso. Para mim, é importantíssimo. Independente do tipo de questões, eu acho que qualquer avaliação é importante para nós (O.P.B).

$\mathrm{Na}$ escola A, por sua vez, os profissionais também falaram sobre a importância da avaliação do MEC, por representar um indicador da situação da escola:

Sim, toda avaliação externa é relevante, até para a gente saber, entre aspas, onde a gente pode melhorar. É um momento que pode não corresponder naquele dia [da aplicação da Prova Brasil] à realidade da escola, mas mesmo assim serve como um indicador (P.A.6).

Ressalta-se que, embora tenham afirmado a importância da avaliação do MEC, os sujeitos supracitados usaram o termo "entre aspas". Isso sugere que não aderiram plenamente ao discurso oficial e que reconhecem a existência de fragilidades nesse processo de avaliação, como se pode observar nas falas seguintes: 
[...] Essa forma de querer avaliar as escolas por um parâmetro universalizado sem considerar as características da escola e o número de alunos... é equivocado. Se eu não estou errada, precisa ter várias maneiras de ser avaliado isso aí (O.P.B).

Essa avaliação também é excludente. Nenhum instrumento avaliativo é capaz de demonstrar a realidade por completo, porque a avaliação deve ser contínua e processual (P.A.6).

Além da atribuição de valor, os profissionais de ambas as instituições também foram perguntados acerca de suas expectativas de resultado sobre a avaliação do MEC. Na escola A, declararam boas expectativas:

A gente sempre tem a esperança, porque o empenho é dado, o trabalho é feito no dia a dia. É cansativo? É. Porque muitos alunos não querem, não entendem a importância da coisa. Então é um trabalho árduo do dia a dia mesmo. Eu realmente espero sempre muito. [...] Acho que compensa, né?! Essa é uma característica nata do professor. Ter esperança, ter expectativa, querer sempre mais e o melhor. Porque se nós perdermos essa vontade, essa esperança, desiste! Nem sairia da cama para trabalhar! As condições e os recursos e a ajuda exterior à escola são assim, quase nada (P.A.1).

Contudo, na escola B, a O.P já esperava um resultado negativo:

Todos já esperavam um resultado insatisfatório [...]. Não sendo repetitiva, mas eu sabia que o resultado não nos traria satisfação. Quer dizer, o resultado em si não nos causou nenhuma surpresa, porque nós já esperávamos por aquilo (O.P.B).

Os professores da escola B não apresentaram elevada expectativa de resultado positivo, porém não revelaram uma expectativa tão desfavorável quanto revelou a Pedagoga. Ao mesmo tempo, reconheciam a existência de dificuldades que poderiam comprometer o resultado final:

Esperar um resultado ruim, a gente nunca espera. A gente quer sempre que tenha um resultado melhor, porém com essas dificuldades que a gente tem aqui... eu não queria acreditar que fosse esse resultado. Eu achava que eles poderiam fazer mais, poderia ser melhor, entendeu? (P.B.4)

De acordo com Wigfield e Eccles (2000), a atribuição de valor sobre um dado objetivo ou tarefa, assim como as expectativas de resultado, estão relacionadas às crenças do indivíduo sobre o quanto ele será bem-sucedido em suas escolhas ou ações e o quanto ele as valoriza. Essas crenças influenciam a motivação, afetando sua persistência e seu desempenho. Percebe-se que, no contexto da pesquisa, os resultados satisfatórios obtidos anteriormente pela escola $\mathrm{A}$ fortaleceram as expectativas dos profissionais, que acreditavam na probabilidade de sucesso. Ainda que questionassem os critérios da avaliação do MEC, verifica-se que ocorreu atribuição de valor à avaliação, pois se engajaram para manter um bom resultado, como pode ser melhor observado mais adiante (itens 4.3 e 4.4). Na escola B, por sua vez, os resultados anteriores não geraram boas expectativas, tampouco motivação.

Vale considerar, ainda, que as experiências de êxito ou fracasso também são fontes importantes de autoeficácia e podem influenciar no comportamento subsequente (BANDURA, 1999; 2012). A crença de autoeficácia é definida como a crença na própria capacidade de organizar e executar ações frente a determinados objetivos (BANDURA, 1999). Destaca-se que o desempenho anterior satisfatório da escola A foi elemento favorável à crença de autoeficácia individual e, principalmente, à autoeficácia coletiva dos profissionais dessa escola, resultando em maior engajamento, conforme relatos dos professores:

A gente sempre quis o primeiro lugar. Mesmo em 2013, a gente já queria o primeiro. Sabemos que temos condições e que nossos alunos também têm condições. Esse resultado de 2015 foi fruto de um trabalho muito grande [...]. (P.A.6).

Outro relato: 
Mais estimulada a gente fica com esse resultado positivo. As professoras daqui e as que vão chegando vão se contagiando. As que estão aqui recebem esse mérito e a gente fica realmente muito motivada. E a produção, não podemos deixar cair, né? Não podemos deixar cair o índice. E aí a gente trabalha para manter e até aumentar o IDEB. É uma motivação muito boa (P.A.1).

As falas das entrevistadas, como se percebe acima, denotam predominantemente orientação à meta de sucesso voltada à performance dos estudantes, ao desejarem que o resultado da escola seja evidenciado positivamente entre as demais escolas da Rede Municipal. Pintrich (2000) considera que esse tipo de meta pode ser produtivo, quando leva os indivíduos a almejarem bons resultados. Percebe-se que o desejo de alcançar uma nota elevada acaba influenciando no desempenho dos professores da escola A, sobretudo porque nessa escola também há o reconhecimento de que o produto é resultado do processo.

$\mathrm{Na}$ escola B não se percebeu a motivação dos professores para o planejamento de ações no período anterior à Prova Brasil, nem tampouco a existência de metas compartilhadas. É possível que tenham ocorrido comportamentos de evitação, ao atribuírem grande importância às dificuldades vivenciadas, associadas a um baixo senso de autoeficácia (BANDURA, 1999).

A orientação do lócus de controle sinaliza uma diferença entre as escolas A e B. De acordo com Lefcourt (2014), as pessoas tendem a perceber o controle sobre as situações como dependente de suas próprias capacidades e esforços, ou como dependente de outras pessoas ou instâncias, ou seja, dentro ou fora do próprio controle. Desse modo, pessoas com lócus de controle mais interno tendem a envolver-se com maior motivação na resolução dos problemas por acreditarem que podem produzir mudanças significativas no alcance de seus objetivos. Na escola B, o lócus de controle dos professores é mais voltado à exterioridade, isto é, percebem que as soluções das dificuldades vivenciadas estão em outras pessoas ou domínios. O relato da O.P. da escola B explicita essa questão:

Nós, O.P.s, somos muito cobradas pelos resultados deles, só que, como eu já falei, não quero ser repetitiva, são vários fatores interferindo, vários fatores. Então, como que pode se pleitear um resultado lindo, maravilhoso, com tantas omissões de vários setores? Então, a gente não pode dar conta de algo que está além dos muros da escola, entendeu? (O.P.B).

Por outro lado, os profissionais da escola A, embora reconheçam a necessidade de ações oriundas de fontes externas à escola, dentro de suas possibilidades conseguem desenvolver estratégias e mostram-se motivados:

[...] a gente tem uma estrutura tão deficiente, mas mesmo assim, com esforço, a gente ainda consegue ter um IDEB alto. Esse ano as provas que as meninas estão fazendo, eu vou te mostrar... umas provas muito caprichadas. A gente está com uma máquina colorida que a gente conseguiu, a gente está pagando. [...] E isso faz a diferença. Eu não sei, parece que eu fico mais motivada. A professora está falando e eles estão lá acompanhando, entendeu? E as professoras nunca estão satisfeitas: “Ah! Eles não estão bons, não. Precisamos melhorar". Isso tudo é muito bacana (O.P.A).

Em síntese, na escola B não se percebeu a mesma motivação observada na escola A. Para preservarem a sua autoestima e sua motivação para tarefas futuras, as pessoas podem controlar suas atribuições de sucesso ou fracasso (PINTRICH, 2000). Por esse motivo, acredita-se que profissionais da escola B tenham enfatizado as adversidades presentes no contexto para protegerem-se de sentimentos de fracasso e culpa que trariam muito sofrimento. Por outro lado, não podem negar as precárias condições de trabalho.

Sabe-se que as crenças podem aumentar a vulnerabilidade ao estresse e afetar as emoções (BANDURA, 2012), no entanto, a autorregulação engloba recursos que potencializam os indivíduos a lidarem de modo satisfatório com os desafios (BANDURA, 1999; 2012; PINTRICH, 2000). Nessa direção, considera-se importante fortalecer os professores e demais profissionais da educação, de modo que eles possam desenvolver novas estratégias para lidarem com as adversidades e tenham maior nível de autorregulação, o que lhes possibilitaria uma atuação mais consciente e motivada.

Além dos aspectos metacognitivos e motivacionais, a fase de planejamento também engloba a dimensão comportamental, apresentada a seguir. 


\section{Dimensão comportamental}

A dimensão comportamental implica o delineamento de estratégias, bem como o planejamento do tempo e dos esforços necessários, dentre outros (PINTRICH, 2000; 2004). Esse processo de preparação na fase inicial do processo de autorregulação é igualmente importante para que os objetivos sejam alcançados.

No que diz respeito ao contexto da pesquisa, quando perguntados sobre o planejamento de ações para a realização da Prova Brasil, na escola A, a Diretora comentou sobre a atuação autônoma dos professores nas ações de planejamento:

As professoras planejavam as ações. Eu deixava o planejamento com elas, porque não precisava estar ali em cima, só falando o que a gente queria. Elas precisavam da direção para tirar xerox, para conseguir material para as atividades e a gente corria atrás das outras turmas para ver, como agora no conselho, quais turmas estão com muitas dificuldades, para tentar ajudar (D.A).

Contudo, nem todos os professores da escola A participaram das ações de planejamento relacionadas à Prova Brasil; entretanto, de acordo com seus relatos, reconheceram a participação coletiva no processo de escolarização:

Eu não planejei ações específicas para a prova [Prova Brasil], porque estava na alfabetização, então o $1^{\circ}$ e $2^{\circ}$ anos não participam. Mas assim... a questão de interpretação... se o profissional não estiver praticando com o aluno, desde a alfabetização, ele vai chegar ao $5^{\circ} \mathrm{com}$ essa defasagem. Então, os professores têm que estar falando uma língua só, com um método só. Todos em prol desta prova, deste exame. Nós não ficamos alheios só porque nós não participamos. É tudo uma língua só. Uma prática só. Um objetivo (P.A.1).

É importante destacar que a professora que atuou no $5^{\circ}$ ano planejou ações específicas para a sua atuação, apontando a responsabilização que existe sobre o professor dessa série frente aos objetivos do MEC. Entretanto, conforme mencionado, existia uma conscientização na escola A sobre a preparação para a avaliação e o reconhecimento de que a aprendizagem é o resultado de um processo. Uma professora do $5^{\circ}$ ano, quando perguntada sobre o planejamento das suas ações, respondeu:

Planejei ações como o simulado. Desde o início do ano, a gente adotou essa questão de fazer simulados tirando questões de anos anteriores da Prova Brasil, inclusive desse livro [um livro com questões semelhantes à Prova Brasil, distribuído pela Secretaria de Educação em 2013], que foi muito bom. Então, a gente sempre se reunia e via qual era a melhor forma de estar preparando os alunos para enfrentar essa avaliação externa (P.A.2).

$\mathrm{Na}$ escola B, por sua vez, quando perguntados sobre o planejamento de ações em decorrência da avaliação do MEC, apenas uma professora respondeu à questão:

A OP vai nas salas. Ela falava pra gente revisar os conteúdos, estudar bastante com as crianças, pra poder ter uma nota melhor. Ela sempre vai nas salas, passa, conversa com a gente. Ela vai em cada turma para falar com cada professor. Até para ter horário para a pessoa conversar com todos. [...] Não tem gente sobrando para ficar com a turma para a gente poder se reunir. A hora de planejamento é o dia da redução de carga horária, entendeu? Aí esse dia a gente conversa com ela, ou, quando não tem tempo, ela vai na sala (P.B.4).

O relato da professora elucida obstáculos existentes na escola que dificultam as ações de planejamento coletivo das práticas pedagógicas. O predomínio de ações individualizadas revela a escassez de esforços coletivos na atuação dos profissionais da escola. Esse individualismo também foi observado em momentos informais, como nos intervalos, em que os profissionais apresentaram baixo grau de interação. Ao mesmo tempo, percebeu-se que as ações eram influenciadas por outros entes e frequentemente não partiam de uma iniciativa autônoma. 
Ainda na escola B, a Diretora disse que não teria condições de opinar sobre ações de planejamento por não ter acompanhado esse processo anterior à avaliação do MEC, visto o seu ingresso ter-se dado posteriormente. A O.P., no que lhe concerne, falou sobre o planejamento de ações que tiveram o objetivo de contribuir para o bom desempenho dos alunos durante a realização da prova:

Para que nós, diretor e coordenador pedagógico, pudéssemos proporcionar uma melhor condição para que o alunado fizesse uma prova num ambiente tranquilo, planejamos algumas mudanças necessárias no dia da prova, como a mudança da sala para um ambiente mais tranquilo (O.P.B).

O relato da Pedagoga focaliza o planejamento de ações voltadas para o controle de condições contextuais desfavoráveis em detrimento de ações pedagógicas, ao contrário da escola A, que preparou os alunos para a realização da Prova Brasil durante o processo de escolarização e de modo intensivo em momento próximo à aplicação da referida prova.

Segundo os relatos de professores das duas escolas, não ocorreu um encontro específico para que houvesse uma conversa acerca da avaliação do MEC com os professores e com a comunidade escolar. Em momentos de encontro, que essencialmente foram planejados com outras finalidades, surgiam questões relacionadas à Prova Brasil que eram discutidas pelos profissionais.

Entretanto, um relato da escola A evidencia a circulação de informações sobre a avaliação do MEC e a influência da Diretora e da Pedagoga nesse processo:

[...] É, a diretora e a pedagoga faziam questão de deixar a escola consciente do processo de avaliação do MEC. Porque os profissionais precisavam entender que era um processo que envolvia a todos. Então, as reuniões envolviam todo mundo, sempre. Era conversado em planejamento, era conversado em conselho... Não era uma coisa assim, todo mês tem uma reunião. Mas sempre que havia uma reunião, ela chamava o grupo para conversar sobre isso (P.A.4).

A Diretora da escola A confirmou:

Não teve reunião específica, mas havia preparação entre os professores, no conselho de classe e depois os professores da turma com a Pedagoga. A gente estava sempre sentando para conversar e as professoras já pegavam o próprio material, não precisava a gente estar procurando para elas. Elas já vinham com o próprio material de trabalho (D.A.).

O relato anterior evidencia o que foi percebido durante a pesquisa: os professores da escola A apresentavam relativa autonomia e iniciativa no trabalho docente. De acordo com a literatura especializada, a autorregulação pressupõe uma atuação autônoma e ativa (PINTRICH, 2000; 2004; ZIMMERMAN, 2000; LOPES DA SILVA, 2004). Essa relativa autonomia provavelmente favoreceu o trabalho docente.

$\mathrm{Na}$ escola $\mathrm{B}$, as professoras não se lembraram se houve reuniões específicas ou se ocorreram durante o período em que estavam afastadas de licença. Uma professora, embora não se lembrasse desse momento, sinalizou a comunicação da Pedagoga às vésperas da avaliação:

Eu não me lembro. Geralmente, os professores são informados [sobre a Prova Brasil] na semana em que vai ocorrer, pela OP. (P.B.2).

A fala da professora deflagrou a falta de planejamento da equipe escolar, o baixo nível de participação da docente no cotidiano escolar, comunicação insuficiente, ou, ainda, a ausência de participação coletiva no processo educativo.

Também foi perguntado aos profissionais se eles perceberam a necessidade de solicitar apoio e recursos à Secretaria de Educação no período anterior à avaliação do MEC. A busca de ajuda pode ser uma estratégia muito útil, sobretudo quando está relacionada ao alcance do objetivo pretendido (PINTRICH, 2004; LOPES DA SILVA, 2004). 
Reconhecendo as dificuldades vivenciadas na época, a O.P. da escola B relatou sua tentativa em buscar ajuda da Secretaria para realizar intervenções:

Sim, solicitamos a presença da secretaria para que estivessem aqui conosco, participando das nossas reuniões também. Algumas pessoas até vieram, participaram da reunião, conversaram com os alunos, conscientizaram (O.P.B).

$\mathrm{Na}$ escola $\mathrm{A}$, os profissionais afirmaram que não planejaram solicitar ajuda à Secretaria. Uma professora do $5^{\circ}$ ano afirmou que a ajuda já estava sendo prestada a partir dos cursos de capacitação. A Diretora da escola A também não percebeu a necessidade de solicitar recursos, pois a escola planejou-se de acordo com as suas possibilidades. No entanto, esse planejamento realizado para prover os materiais de uso contínuo também foi motivado pelo receio de não os receber da Secretaria no momento em que precisariam:

\begin{abstract}
Não percebemos a necessidade de solicitar apoio, porque, por exemplo, a parte de verba, a gente já esquematizava o que a gente ia precisar... folhas, material pedagógico para os professores... então, a gente já priorizava isso antes. De um ano para o outro, a gente planeja a quantidade de material que vai precisar. Então, a gente já fazia compra e deixava guardado para outro ano. Vai que a Secretaria não tenha como mandar folha, lápis e borracha para o trabalho do dia a dia? A gente já estava preparado para não faltar para os alunos (D.A).
\end{abstract}

É importante destacar que, de modo geral, no que diz respeito aos aspectos comportamentais relacionados ao planejamento, os entrevistados não mencionaram o planejamento do tempo e do esforço, assim como do próprio comportamento. Na escola A, percebeu-se que muitas ações foram planejadas de acordo com as necessidades observadas frente ao objetivo perseguido e deflagraram a proatividade dos profissionais. $\mathrm{Na}$ escola $\mathrm{B}$, a ausência de um objetivo compartilhado afetou o planejamento de ações e o envolvimento dos profissionais em relação à avaliação do MEC. Sabe-se que a autorregulação do comportamento dos professores constitui um processo de influências múltiplas, o que não deve ser desprezado.

Em seguida, serão apresentados os aspectos observados, relacionados ao comportamento dos profissionais, no que diz respeito ao contexto em que estavam inseridos.

\title{
Aspectos contextuais
}

Segundo os relatos dos profissionais entrevistados, inúmeros foram os fatores do contexto físico e social que influenciaram na atuação docente. No contexto da pesquisa, diversos aspectos contextuais foram percebidos pelos profissionais na fase de planejamento, relacionados ao momento anterior à avaliação do MEC.

Os professores de ambas as escolas se queixaram de modo recorrente sobre as reais condições de trabalho existentes. Os profissionais da escola A falaram sobre a falta de estrutura adequada para o seu trabalho e de condições socioculturais vivenciadas pelos estudantes, como relatou uma professora:

Desde o planejamento, eu percebia a falta de estrutura no dia a dia dessas crianças, que, na minha opinião, podem levar ao fracasso e à dispersão. Muitas vezes, a criança chega chorosa, muitas vezes, chega deprimida e você não consegue saber, identificar o que está acontecendo na mente dela. Mas, em relação à escola, eu acho que realmente falta uma boa estrutura e recursos. Falta livro para uma pesquisa. Não tem outras fontes. Eu tenho só quadro e uma caneta, sabe? Eu não tenho um computador para levar essas crianças para exemplificar o que eu acabei de falar. Muitas vezes, até mostro o meu celular, vou passando de carteira em carteira (P.A.1),

Os professores da escola B, embora tenham mais espaço nas salas de aula e os alunos usufruam de um grande local para a prática de atividades físicas, lamentam-se da degradação em que se encontra o prédio e do desrespeito dos estudantes ao patrimônio público. A má conservação do 
ambiente, ou a sua inadequação, também influenciam no bem-estar de seus frequentadores, segundo os relatos dos professores:

Eu percebo que muitas situações podem atrapalhar o andamento das atividades. A gente faz o que a gente pode e o que a gente não pode. Até pela sala ali, você já teve uma ideia. Aqui, a estrutura não é muito boa, porque é uma escola que precisa de uma reforma. Aqui, de vez em quando entra alguém. A gente não sabe quem quebra as coisas, entendeu? A minha sala mesmo não tem porta. Já arrumei a sala, mas você nem diz. A gente fala tanto, conversa tanto. Todos os professores falam “Gente, não vai na sala de ninguém, não mexe em nada!". Eles, não sei, parece que têm o prazer de destruir! Não tem aquele respeito. Por isso que eu estou falando de respeito, tudo vem de casa. Se os pais não participam, os filhos não estão nem aí (P.B.4).

O baixo nível de participação dos pais ou responsáveis na aprendizagem escolar foi um fator do contexto social enfatizado pelos profissionais das escolas. Uma professora relatou:

É fácil perceber a falta da presença dos pais. Várias vezes os alunos levam tarefa para casa e não trazem. Falta a presença dos pais no dia a dia (P.B.2).

Ainda que os profissionais de ambas as escolas se queixem de dificuldades relativas ao contexto, cabe considerar que, na escola A, a participação das famílias mostrou-se um pouco melhor em comparação à escola B. Isso possivelmente decorreu, em parte, do fato de que a direção da escola A mantinha uma relação de maior proximidade com os pais ou responsáveis, oportunizando horários flexíveis de atendimento, o que foi relatado por uma professora:

[...] A gente também entende que muitos não podem vir por causa dessa questão do horário. "Ah, marcou tal dia e tal hora, mas eu não posso... mas eu posso tal horário, falar rapidinho...". Isso é importante. Você vê que são pais que correm atrás do direito dos filhos. Que mesmo com toda a dificuldade, eles vão atrás e buscam saber. Tem pais que são muito participativos (P.A.2).

Ainda sobre a percepção dos sujeitos a respeito de fatores contextuais que poderiam interferir nos resultados da avaliação do MEC na fase de planejamento, na escola A, profissionais falaram sobre sua preocupação com a evasão escolar:

Então... a nossa preocupação foi em relação à evasão. Identificamos e corremos atrás desses alunos faltosos. Essa preocupação com a evasão acabou sendo da escola toda. A partir da Prova Brasil, a gente começou a trabalhar muito essa questão da evasão, tanto que, eu não tenho certeza absoluta, mas na nossa escola, hoje, a evasão é praticamente zero (P.A.6).

Outra professora relata essa mesma preocupação com o número de faltas, focalizando, igualmente, os riscos de uma diminuição da nota no IDEB:

Eu percebia a ausência, o número de faltas de alguns alunos... isso poderia prejudicar e a gente ainda está tentando mostrar para os pais a importância de não faltar, por prejudicar a escola. $\mathrm{O}$ número de faltas é preocupante. Conversamos, pessoalmente, com cada pai. E mostramos a eles a importância de manter a nota da nossa escola (P.A.4).

Observou-se que a evasão não foi mencionada pelos professores da escola B como uma preocupação; por conseguinte, não relataram estratégias de intervenção. Entretanto, a baixa frequência também deve ocorrer entre os alunos dessa instituição. Os profissionais dessa escola citaram outros fatores contextuais, como o funcionamento do sistema educacional:

Eu percebia que um dos agravantes é essa questão dessa aprovação automática... eu acho que devem ser revistas algumas coisas que são feitas da pré-escola até o $1^{\circ}$ ano de escolaridade, que são as séries fundamentais para a criança desenvolver a leitura do conhecimento, dos primeiros conceitos básicos. Eu acredito que o mau desempenho hoje é devido a essa falta de preocupação sobre o que nós estamos passando para o nosso aluno. Qual a qualidade de ensino que nós 
estamos dando para os nossos alunos hoje? A minha preocupação é essa. Eu vejo muitos professores que não têm perfil pra alfabetizar uma criança. A maioria das crianças que nós temos, elas não foram alfabetizadas. Como que eles vão ler a prova? Ele não tem essa noção. Isso certamente contribui para um resultado ruim (P.B.1).

De modo geral, pode-se observar, através das entrevistas, a existência de muitos fatores contextuais que possivelmente poderiam interferir nos resultados da avaliação do MEC. Contudo, é importante destacar outras diferenças entre as escolas. A escola A, além de ter sinalizado aspectos relativos à participação da família na escolarização, conseguiu planejar-se para intervir sobre essa situação e sobre as outras condições contextuais, conseguindo, inclusive, identificar a baixa frequência e intervir sobre ela, assim como planejar o fornecimento de recursos básicos para os estudantes e professores, como foi citado na categoria anterior.

Embora tenham citado tais dificuldades, os profissionais da escola A falaram também sobre ações voltadas para a solução desses obstáculos, ou seja, apresentaram atitude proativa, o que não foi percebido nos relatos de profissionais da escola B. Nela, os profissionais afirmaram que fazem o possível, sinalizando a existência de muitas situações que consideram estar fora de seu alcance. A rotatividade dos professores citada anteriormente parece estar relacionada às condições do contexto, ao mesmo tempo em que representa mais um agravante no processo educacional, numa reciprocidade de influências desfavoráveis entre causas e efeitos. Em observação das rotinas de funcionamento da escola B, foi possível perceber, no ano de 2017, a permanência de fatores listados pelos profissionais da escola quando ocorreu a avaliação em 2015.

Embora a escola A apresente muitos aspectos favoráveis à autorregulação, assim como a escola B, é afetada por inúmeras demandas, regras e normas, que desconsideram a autonomia dos docentes, diretores e orientadores pedagógicos na escola. Quando as determinações externas são consideradas sem que ocorra uma adequada reflexão por parte dos profissionais, o resultado desse processo pode ser uma compreensão superficial das políticas educacionais envolvidas. Na escola $\mathrm{A}$, a adesão aos objetivos da avaliação resultou em um engajamento de toda a equipe escolar num processo de planejamento para a preparação dos alunos e para a minimização de fatores que poderiam interferir negativamente no resultado do IDEB, como o combate à evasão escolar.

Embora esses comportamentos tenham produzido resultados satisfatórios no dia a dia da escola, percebeu-se que, para uma adequada autorregulação dos professores, eles necessitam refletir mais sobre suas ações e questionar os objetivos envolvidos desde o momento do planejamento, como preconiza a teoria da Autorregulação (ZIMMERMAN, 2000). É importante lembrar que o objetivo dos profissionais dessa escola foi trabalhar para que a instituição mantivesse um bom resultado entre as escolas do município. De fato, a avaliação do MEC produziu efeitos sobre a realidade dessa escola, que também é influenciada pelo discurso oficial.

$\mathrm{Na}$ escola B, observou-se que a falta de planejamento e a baixa autorregulação dos profissionais ocorre além dos momentos da realização da avaliação do MEC. Os professores geralmente são mobilizados pela Pedagoga, que apresenta as tarefas a serem cumpridas, sem que ocorram momentos de reflexão e questionamento sobre os objetivos envolvidos. Tampouco se mobilizam coletivamente para buscar soluções para os problemas que enfrentam. Importa considerar que todos os indivíduos apresentam algum nível de autorregulação. No entanto, é importante frisar que, nas realidades observadas, as regulações externas têm forte influência sobre a atuação docente, o que também já foi observado em outros contextos por Amaro (2017).

\section{Ampliando as discussões sobre a avaliação do MEC}

Estudos sobre a avaliação na perspectiva da autorregulação da aprendizagem preconizam uma avaliação formativa, que conduza à superação de dificuldades e ao desenvolvimento, acompanhando todo o processo (HAT'TIE; TIMPERLEY, 2007; HADJI, 2011).

Ao analisar a avaliação do MEC no Ensino Fundamental, pode-se afirmar que se trata de uma avaliação somativa, que evidencia resultados numéricos em detrimento de uma análise profunda sobre a realidade das escolas. O feedback disponibilizado pelo MEC às instituições e redes de ensino não 
estimula os profissionais da educação a uma reflexão sobre a complexa realidade em que se encontram. Os resultados, genéricos, não sinalizam fragilidades e competências (ALMEIDA; DALBEN; FREITAS, 2013), nem tampouco indicam caminhos possíveis para mudanças necessárias.

No atual processo de avaliação das escolas, têm-se como foco o produto da aprendizagem, tendo em vista que, no primeiro ciclo do Ensino Fundamental, o MEC avalia o $5^{\circ}$ ano, sua última série. Essa regra também influencia a percepção de profissionais da educação e das Secretarias de Educação, que centralizam seus esforços na capacitação dos professores dessas turmas, de modo que eles possam preparar os estudantes para a realização da Prova Brasil, sendo mobilizados por regulações externas (AMARO, 2017). Isso contribui para uma maior responsabilização dos professores do $5^{\circ} \mathrm{em}$ relação ao resultado que supostamente revelaria o nível da qualidade da educação oferecida pela escola como um todo.

$\mathrm{Na}$ preparação dos estudantes, professoras relataram dificuldades em construir estratégias de acordo com os descritores da Prova Brasil. Essa dificuldade não deveria existir, visto que eles deveriam estar de acordo com os currículos mínimos trabalhados nas escolas. Tal situação mostra um descompasso entre as práticas cotidianas de avaliação desenvolvidas pela escola e a proposta de avaliação do MEC.

$\mathrm{Em}$ todas as dimensões investigadas relacionadas à fase de planejamento, a escola A apresentou diversos aspectos favoráveis ao ensino e à aprendizagem: deliberadamente, mostra-se motivada a alcançar um bom resultado no IDEB, e, para isso, trabalha continuamente com os alunos, o que resulta em oportunidades de aprendizagem. Também há, nessa escola, um consenso de que os resultados obtidos são fruto dos esforços coletivos empreendidos pelos profissionais na formação do estudante. As interações entre eles foram observadas no cotidiano escolar e em seus discursos, evidenciando um senso de pertencimento.

$\mathrm{Na}$ escola $\mathrm{B}$, os esforços associados à avaliação do MEC aconteceram em momento próximo à realização da Prova Brasil, não tendo sido observado um engajamento coletivo para a elaboração de um planejamento frente aos objetivos educacionais. Percebeu-se que a elevada rotatividade de professores influencia na continuidade das ações e na construção de vínculos entre os profissionais, dentre outros inúmeros fatores envolvidos.

Ainda na escola $\mathrm{B}$, mesmo que os professores saibam que a instituição não teve um resultado favorável no IDEB, o mesmo não foi devidamente discutido pela equipe escolar. Na escola $\mathrm{A}$, embora seus profissionais conheçam os resultados anteriores do IDEB e tenham sido afetados de modo positivo em suas motivações para a construção do planejamento, também não ocorreu uma análise profunda do resultado obtido. Contudo, vale ressaltar que os resultados positivos alcançados pela escola A impulsionaram os profissionais a continuarem se esforçando para a obtenção de bons resultados. Por outro lado, na escola B, os resultados negativos não impulsionaram à superação, diferentemente de outras realidades observadas (MESQUITA, 2012).

Outro aspecto é a ênfase atribuída pelos profissionais da escola B aos obstáculos do contexto. Ao mesmo tempo em que se percebeu, na referida escola, a falta de oportunidades para ações coletivas e para a interação entre os próprios professores, constatou-se a escassez de iniciativas de planejamento visando à superação das dificuldades existentes, para além dos objetivos da avaliação do MEC. Além disso, percebeu-se a falta de autonomia e de iniciativa dos professores na construção de estratégias de enfrentamento para os inúmeros problemas citados pelas mesmas. Não raro, a solução dos problemas vivenciados foi atribuída a fatores externos.

É importante que o professor esteja sintonizado com o contexto e tenha possiblidade de participar coletivamente da busca de estratégias para a superação das dificuldades. $\mathrm{Na}$ escola $\mathrm{B}$, foram raros esses momentos. $\mathrm{Na}$ escola $\mathrm{A}$, o nível de interação entre a equipe escolar mostrou-se mais efetivo, influenciando nas ações realizadas, bem como no fortalecimento da equipe frente às dificuldades. Assim como a escola observada por Mesquita (2012), a existência de uma gestão democrática, sob uma atuação incentivadora, contribuiu para o sucesso da equipe na escola $\mathrm{A}$.

Vale considerar, ainda, que a responsabilização sobre os profissionais da educação não garante a autorregulação em sua atuação. De modo geral, para a construção do planejamento, pressupõese que o profissional da educação deva conhecer e discutir sobre os objetivos que permeiam o seu trabalho, sejam eles objetivos oriundos do MEC ou do cotidiano da escola. Substancialmente, a 
construção de objetivos para a própria atuação é imprescindível para a autorregulação do professor. Traçar o próprio curso de ação, planejar as estratégias a serem utilizadas e refletir continuamente sobre o próprio trabalho também requer um ambiente facilitador e inclusive, políticas educacionais que favoreçam esse processo. Os resultados revelam a influência da dimensão contextual sobre os docentes. Nesse sentido, é importante reconhecer que, embora o professor seja muito importante para o sucesso do processo educacional, ele não deve estar sozinho nessa jornada.

\section{CONSIDERAÇÕES FINAIS}

Além dos aspectos mencionados anteriormente, é importante destacar aqueles que podem ser melhor trabalhados em ambas as escolas e que também se aplicam a outros contextos. Faz-se necessária uma criteriosa análise dos objetivos da avaliação do MEC. Os profissionais são mobilizados para a missão de preparar alunos para a Prova Brasil sem, no entanto, conhecer os objetivos do SAEB com profundidade. Além disso, é fundamental a reflexão sobre os próprios objetivos da equipe escolar.

O trabalho dos professores pressupõe autonomia para construir estratégias e reflexão contínua sobre a própria atuação. Em suas falas, os profissionais mostraram-se muito mais sintonizados com os aspectos do contexto, em detrimento dos seus recursos pessoais. As entrevistadas não mencionaram a reflexão sobre a própria cognição, afetos e comportamentos.

A partir da observação do cotidiano das escolas, pode-se inferir que a falta de clareza ou de reflexão sobre objetivos do MEC demonstra a necessidade de investir na autorregulação do comportamento dos professores. Ainda que a autorregulação pressuponha autonomia e iniciativa, para além de aspectos pessoais, os profissionais são influenciados pela dinâmica de funcionamento da instituição, incluindo a gestão escolar, as interações sociais, as representações sobre o contexto e a participação da Secretaria de Educação. Ao mesmo tempo, os achados da pesquisa também reforçam a importância da formação continuada e do desenvolvimento de estratégias que favoreçam o trabalho do professor, considerando as suas necessidades e desafios.

A autorregulação pressupõe um processo de autoavaliação que só ocorrerá efetivamente na medida em que a escola voltar-se de modo reflexivo e crítico sobre a própria realidade. Considerando que a avaliação do MEC representa um recorte da realidade, a escola pode construir outros mecanismos que possibilitem uma análise mais apropriada da qualidade dos processos educacionais (ALMEIDA; DALBEN; FREITAS, 2013; AMARO, 2017).

Para isso, cabe repensar o SAEB e o modo pelo qual as avaliações externas influenciam na realidade das escolas - o que já foi sinalizado por pesquisas anteriores (MESQUITA, 2012; ALMEIDA; DALBEN; FREITAS, 2013; AMARO, 2017). A avaliação não é um fim em si mesma. Acredita-se que ela pode fomentar melhorias no processo educacional, mas mudanças no sistema de avaliação são necessárias, incluindo os processos de comunicação envolvidos. Para que as escolas reflitam sobre os índices obtidos e construam objetivos efetivos, devem ser incentivadas a pensar coletivamente sobre a sua realidade. Um feedback representado por um índice numérico não conduz à autorregulação, nem tampouco à superação de complexas dificuldades.

\section{REFERÊNCIAS}

ALMEIDA, L. C.; DALBEN, A.; FREITAS, L. C. de. O IDEB: limites e ilusões de uma política educacional. Educação \& Sociedade, v. 34, n. 125, p. 1153-1174, 2013.

AMARO, I. Avaliação em larga escala e trabalho docente. Quaestio - Revista de Estudos em Educação, v. 19, n. 2, p. 417-436, 4 set. 2017. Disponível em: < https://doi.org/10.22483/21775796.2017v19n2p417-436>. Acesso em: 29 set. 2019.

BANDURA, A. Ejercicio de la eficacia personal y colectiva en sociedades. In: BANDURA, A. (Org.). Auto-eficácia: Cómo afrontamos los cambios en la sociedad actual. Tradução: Jasone Aldekoa. Bilbao: Desclée de Brouwer, 1999. p. 19-54. 
BANDURA, A. On the Functional Properties of Perceived Self-Efficacy Revisited. Journal of Management, v. 38, p. 9-44, 2012. Disponível em: < https://doi.org/10.1177/0149206311410606>. Acesso em: 03 out. 2018.

BANDURA, A. Social cognitive theory: An agentic perspective. Annual review of psychology, v. 52, n. 1, p. 1-26, 2001. Disponível em: <https://doi.org/10.1146/annurev.psych.52.1.1>. Acesso em: 15 nov. 2018.

BANDURA, A. Social foundations of thought and action: A social cognitive theory. Englewood Cliffs, NJ: Prentice Hall, 1986.

BARDIN, L. Análise de Conteúdo. Lisboa: Edições 70, 1979.

BOGDAN, R. C.; BIKLEN, S. Investigação qualitativa em educação. Porto: Porto Editora, 1994.

FERNANDES, R. A universalização da avaliação e a criação do Ideb: pressupostos e perspectivas. Em Aberto, v. 29, n. 96, p. 99-111, 2016.

HADJI, C. Ajudar os alunos a fazer a autorregulação da sua aprendizagem: Por quê? Como? (visando um ensino com orientação construtivista). Tradução Laura Solange Pereira. Pinhais-PR: Ed. Melo, 2011.

HATTIE, J.; TIMPERLEY, H. The power of feedback. Review of educational research, v. 77, n. 1, p. 81-112, 2007.

INEP - Instituto Nacional de Estudos e Pesquisas Educacionais Anísio Teixeira Legislação e Documentos. Resumo Técnico: resultados do Índice de Desenvolvimento da Educação Básica 20052015. Setembro, 2016. Disponível em:

<http://download.inep.gov.br/educacao_basica/portal_ideb/planilhas_para_download/2015/ resumo_tecnico_ideb_2005-2015.pdf>. Acesso em: 12 fev. 2017.

LEFCOURT, H. M. Locus of control: Current trends in theory \& research. 2. ed. New York: Psychology Press, 2014.

LOPES DA SILVA, A. A auto-regulação na aprendizagem: a demarcação de um campo de estudo e de intervenção. In: LOPES DA SILVA, A.; DUARTE, A. M.; SÁ, I. Aprendizagem auto-regulada pelo estudante: perspectivas psicológicas e educacionais. Porto-Portugal: Porto Ed., 2004. p. 17-39.

MCCASLIN, M. Co-regulation of student motivation and emergent identity. Educational Psychologist, v. 44, n. 2, p. 137-146, 2009. Disponível em:

<https://doi.org/10.1080/00461520902832384>. Acesso em: 22 nov. 2018.

MESQUITA, S. Os resultados do Ideb no cotidiano escolar. Revista Ensaio: Avaliação e Políticas Públicas em Educação, v. 20, n. 76, p. 587-606, 2012.

OLIVEIRA, R. P. de. A utilização de indicadores de qualidade na unidade escolar ou porque o IDEB é insuficiente. In: BAUER, A.; GATTI, B. A. (Orgs.). Vinte e cinco anos de avaliação de sistemas educacionais no Brasil: implicações nas redes de ensino, no currículo e na formação de professores. Florianópolis: Insular, 2013. p. 81-100.

PINTRICH, P. R. A conceptual framework for assessing motivation and self-regulated learning in college students. Educational Psychology Review, v. 16, n. 4, p. 385-407, 2004. 
PINTRICH, P. R. The role of goal orientation in self-regulated learning. In: BOEKAERTS, M.; PINTRICH, P. R.; ZEIDNER, M. (Orgs.). Handbook of Self-Regulation. [s.l]: Academic Press, 2000. p. 452-502.

SCHNEIDER, M. P.; NARDI, E. L. O IDEB e a construção de um modelo de accountability na educação básica brasileira. Revista Portuguesa de Educação, v. 27, n. 1, p. 7-28, 2014.

SCHUNK, D. H.; ZIMMERMAN, B. J. Social origins of self-regulatory competence. Educational psychologist, v. 32, n. 4, p. 195-208, 1997.

SOARES, J. F.; XAVIER, F. P. Pressupostos educacionais e estatísticos do Ideb. Educação \& Sociedade, v. 34, n. 124, p. 903-923, 2013.

WIGFIELD, A.; ECCLES, J. S. Expectancy-value theory of achievement motivation. Contemporary educational psychology, v. 25, n. 1, p. 68-81, 2000.

ZIMMERMAN, B. J. Attaining self-regulation: A social-cognitive perspective. In: BOEKAERTS, M.; PINTRICH, P. R.; ZEIDNER, M. (Orgs.). Handbook of self-regulation. New York: Academic Press, 2000, p. 13-39.

Submetido: $18 / 02 / 2019$

Aprovado: 18/10/2019 